\title{
A prospective study of dengue infection in Malaysia: A structural equation modeling approach
}

\author{
Asyraf Afthanorhan $^{1 * \mathbb{D}}$, Nazim Aimran $^{2}{ }^{(\mathbb{C}}$ \\ ${ }^{1}$ Faculty of Business and Management, Universiti Sultan Zainal Abidin (UniSZA), Terengganu, Malaysia \\ ${ }^{2}$ Advanced Analytics Engineering Centre, Faculty of Computer and Mathematical Sciences, Universiti Teknologi MARA, Shah Alam, \\ Malaysia
}

\begin{abstract}
Background: Dengue fever has been a major health threat to Malaysia over one century since 1902. This situation is getting worse every year so that the government has taken an affirmative action to tackle this particular issue. The purpose of this study was to investigate the effect of government support, climate changes, public attitude, population growth, and environment on dengue infection. Also, this study considered the environment as a mediator construct as the past literature revealed its role in dengue infection model.

Methods: In order to identify the relationship between exogenous and endogenous constructs, structural equation modeling (SEM) was used. Also, in order to identify the factors affecting dengue infection, measurement and structural model evaluation were applied. Using stratified sampling method, 670 questionnaires were distributed among prospective respondents from eastern region, but in turn, only 505 cases could be used after data cleaning process.

Results: Considering environment factor as a mediator, the results show that public attitude and population growth have a significant impact on the environment, while government support, public attitude, and environment factors have a significant impact on dengue infection. Population growth was the most important factor affecting dengue fever.

Conclusion: According to the results, dengue fever that emanating from four exogenous and one mediator constructs are adequate to discuss on respondent perception of dengue fever in Malaysia. Keywords: Dengue infection, Population growth, Malaysia, Government, Surveys and questionnaires Citation: Afthanorhan A, Aimran N. A prospective study of dengue infection in Malaysia: A structural equation modeling approach. Environmental Health Engineering and Management Journal 2020; 7(3): 161-169. doi: 10.34172/EHEM.2020.19.
\end{abstract}

Article History:

Received: 19 April 2020

Accepted: 13 July 2020

ePublished: 23 September 2020

\section{Introduction}

Dengue fever has been a major health threat to Malaysia over one century since 1902 so that the government has taken a serious action to tackle this particular issue (1). According to a study by Heilman et al (2), dengue infection also known as breakbone fever has been primarily occurred in the equatorial regions of Africa, the Americas, Southeast Asia, and the Western Pacific region. The incidence of dengue fever has increased dramatically from 50 million to 528 million since the 1960 s. The number of patients with dengue fever is not only increasing in Malaysia but also in other countries, either developed or developing countries. The World Health Organization (WHO) has proposed several strategies to control dengue infection. Therefore, this study was conducted to identify the most important factors affecting the public health in term of dengue infection. In the present study, the second- generation statistical method, namely structural equation modeling (SEM) with AMOS 21.0 was used to achieve the study goals and evaluate its capability to estimate the causal effects in a complex model.

Recently, Malaysia has faced with problems of dengue infection that has been spread in every state since 2014 . According to the Ministry of Health report, Selangor is the first place that has the highest number of dengue cases $(3,4)$. In order to determine the most important factors affecting the spread of dengue fever, SEM analysis was performed. In this stage, four exogenous constructs including government support, climate changes, public attitude, and population growth, and one mediator construct including environment that will be imposed on dengue fever as an outcome of this study, were selected. The growing number of research papers using SEM in research fields regarding its strengths and their robustness 
call for a critical assessment of the way the method is applied in the dengue infection research. Reflecting critically on the use of SEM is crucial, as this could provide insight for the applied researchers to develop and complete their research project, as well as helping them to perform more comprehensive research on the diversity of variables.

Thus, there are three objectives that will be undertaken using the same application due to the robustness of maximum likelihood estimator (MLE). A consistent estimator will help us to generate proper results that can be used for managerial decision. The present study was conducted to identify whether the study discussed is appropriate for testing the hypothesis, to determine the causal effects of government support, climate changes, public attitude, population growth, and environment on dengue fever, and to examine the most important factor affecting dengue fever and the environment through parameter estimation and hypotheses testing.

Government support and public attitude

Gubler stated that government and public health officials can take necessary measures to control dengue epidemic using a highly visible method (5), which is confirmed by Focks et al and Iqbal and Islam. They stated that the control of the epidemic can be fulfilled by the central government without the need to public cooperation $(6,7)$. On the contrary, we believe that every individual and community should have cooperation with central government to solve this particular problem in a short period, which is confirmed by Kyle and Harris who stated that the public should not over rely on the government solely (8). Indeed, government is one of the important factors for providing funds for public health services but also can be a generator to push the global health community to move towards horizontal programs, which integrate education and community participation. Parks et al and Hossain et al also stated that public and government should cooperate with each other to prevent the spread of dengue infection $(9,10)$. Therefore, the research hypotheses of government support and public attitude was proposed as follows:

$\mathrm{H}_{1}$ : Government support has a significant impact on dengue fever

$\mathrm{H}_{1}$ : Public attitude has a significant impact on dengue fever

\section{Climate changes}

Patz et al identified climate changes as an effective predictor for the incidence of dengue fever in Taiwan. They also identified this factor as a significant indicator for the increasing incidence of dengue fever. They also reported that climate changes influence the spread of dengue fever (11). Thus, the present study was conducted to find whether this factor as an exogenous construct affects the incidence of dengue fever in Malaysia. Therefore, the research hypothesis of climate changes and dengue fever was proposed as follows:

$\mathrm{H}_{1}$ : Climate changes has a significant impact on dengue fever

Population growth

According to Gubler and Meltzer, demographic and social changes such as population growth, urbanization, and modern transportation contributed greatly to the increased incidence of dengue activity. The population growth basically occurs in urban areas (12). Additionally, it was proposed that the emergence of dengue fever in the waning years of the $20^{\text {th }}$ century has been closely tied to the population growth, urbanization, and air travel $(5,12)$. Thus, it cannot be denied that population growth is not relevant to dengue fever. Previous studies also reported an association between population growth and dengue fever (13-16), which is consistent with the results of this study. Therefore, the research hypothesis of population growth and dengue fever was proposed as follows:

$\mathrm{H}_{1}$ : Population growth has a significant effect on dengue fever

Environment

Some studies have intended to relate the environment as the main cause of incidence of dengue fever. Nakhapakorn and Tripathi reported a relationship between dengue fever and environment using GIS application (17). They claimed that environment has a positive relationship with dengue fever, which is consistent with the results of other studies $(18,19)$. All of them introduced the environment as the main cause of dengue fever. Thus, in this study, environment was applied as a mediator construct since it is perceived that it can be effected by other exogenous constructs such as government support, public attitude, climate changes, and population growth, and at the same time, this construct has a positive relationship with dengue fever as an outcome of the study. Since the environment is considered as a mediator construct, it was attempted to impose these exogenous constructs on the environment as well. In sum, the research hypotheses proposed for the environment construct are as following:

$\mathrm{H}_{1}$ : Environment has a significant impact on dengue fever $\mathrm{H}_{1}$ : Government support has a significant impact on the environment

$\mathrm{H}_{1}$ : Climate change has a significant impact on the environment

$\mathrm{H}_{1}$ : Public attitude has a significant impact on the environment

$\mathrm{H}_{1}$ : Population growth has a significant impact on the environment

\section{Materials and Methods}

In this study, stratified sampling technique which is one of the probability techniques was adapted. The minimum 
sample size required for this study was 450 samples. The calculation of sample size was suggested (20), in which the total sample size should be 10 times of the number of indicators. In this case, 45 items with Likert scale were constructed.

Thus, the minimum sample size was calculated as $45 \times 10=450$. Thus, 900 questionnaires were printed and distributed. However, data were collected from eastern regions such as Kelantan, Terengganu, and Pahang using almost 670 questionnaires but still accepted because the collected data were higher than the minimum sample size. After data collection, data cleaning was performed to remove the outlier so that the obtained data achieved the assumption of normal distribution. After data cleaning, only 505 datasets could be used for the inferential statistics. Beforehand, the questionnaire was distributed by developing strata with the same proportion of gender that applied to three states.

\section{Results}

In this study, SEM was applied to validate the measurement model and analyze the causal effects of each constructs involved in the study. SEM is adopted in the areas of marketing (21), management (22,23), entrepreneurship (24), tourism (25-27), and business research (28-30). Specifically, this model is composed of two models: measurement and structural models. Measurement model was developed according to the theoretical framework of this study.

For this purpose, in the initial phase (designing questionnaire), the researchers were advised to use a proper psychometric development (Likert scale) so that the intention of respondents can be measured accurately (20). They also suggested that the larger scale of measurement lead to the production of accurate results than the smaller scale of measurement.

Therefore, this research applied 10 point of measurement scale from 1 (strongly disagree) to 10 (strongly agree). In designing the questionnaire levels, 21 questions were composed in section B, which involves 6 constructs. Specifically, the government support construct consisted 5 items; climate changes, public attitude, environment, and population growth has 3 items, respectively; and dengue infection has 4 items. These items in the questionnaire were designed based on the previous research and were enhanced based on the suitability of the current research with the help of an expert in the field of dengue research in the stage of questionnaire development.

These particular questionnaires have two sections, namely section A (demographic profile) and section B (dengue infection). During implementation of the exploratory study, exploratory factor analysis (EFA) was used to minimize the number of item in the questionnaire and identify the relevant items under each component yielded. This particular method has been implemented across discipline such as psychological research $(31,32)$, personality assessment (33), entrepreneurship (34), etc. Then, confirmatory factor analysis (CFA) was performed as exhibited in Figure 1, in which the requirements of fitness index and exploratory phase (removal items) were achieved.

\section{Confirmatory factor analysis}

During EFA approach with principle component analysis and Varimax rotation, five constructs were discovered and some of the items were composed in the same set of components. Items in the same components carried the same connotation. In order to confirm the research theory, CFA was used to confirm whether the items are worth to be retained for the subsequent analysis. At this stage, CFA was taken seriously by following the procedure strictly so that the items retained were really appropriate to conduct structural model.

The global criterion or fitness index were performed to identify whether the model constructed achieved the requirements. In covariance-based structural equation modeling (CBSEM), there is an abundance of fitness index to validate the measurement model in the evaluation phase. Fitness index is an important factor in academic research to convince researchers how well-defined the model is so that the researchers can claim that their model is valid enough for the final stage (estimation and hypothesis testing). Additionally, there are three categories for fitness index including absolute fit (RMSEA and AGFI), parsimonious fit (chi-square/df), incremental fit (TLI, CFI, NFI, GFI, and ILI), in which all of the categories should meet the minimum requirements. According to a study by Holmes-Smith et al, researchers should report their findings by choosing at least one fitness index from each categories (35).

The results obtained from CFA method are shown in Figure 1. As shown in this figure, the values for each fitness index are satisfying and meet all the threshold values. To do so, some critical assessments have been implemented by removing poor loadings. According to a study by Nasir et al, the outer loading of 0.60 is considered as a threshold for the CFA approach (36). Thus, any items that do not meet the threshold requirement will be eliminated directly from the model so that only the remaining item (outer loading above 0.60 ) in each construct can be handled. However, the proper procedure is needed to be addressed during the multidimensional procedure whereby deleting item should be implemented once at a time. This is because the simultaneous removal of many items can affect the quality of measurement model due to the deep changes in the calculation of covariance algorithm. In this case, only 18 items were retained after removing 3 items from the model due to poor loading. The model met the requirements for each category as parsimonious fit $($ chi-square $/ \mathrm{df}=2.754<3.0)$, absolute fit $($ RMSEA $=$ $0.074<0.08)$, and incremental fit $(\mathrm{CFI}=0.951>0.95$, NFI $=0.935>0.90$, TLI $=0.938>0.90)$. 


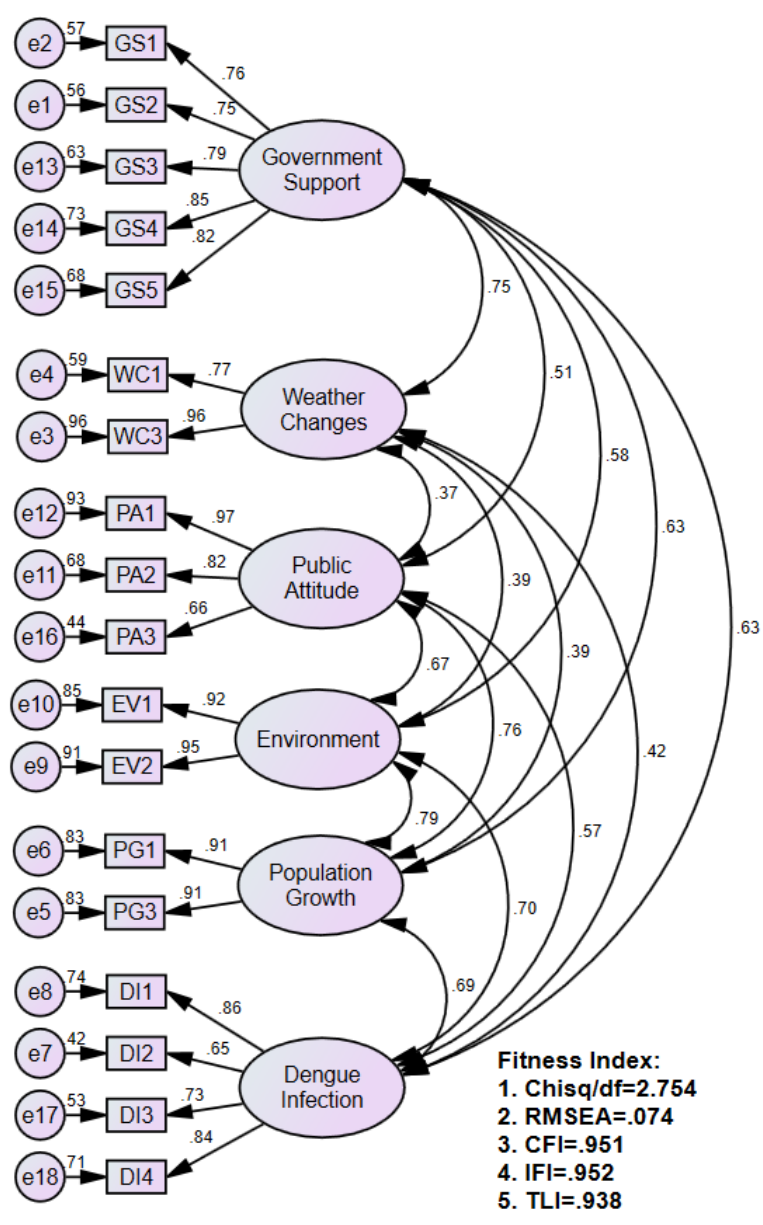

Figure 1. Confirmatory factor analysis.

In particular, the strength of fitness is strongly influenced by the strength of factor loadings. Consequently, the measurement model cab be reported admissible once the fitness index meet the requirement. It means that the fitness index is the primary observed indicator in statistical modeling followed by an important variable (high factor loading). In addition, high factor loadings would provide a high variation in the measurement model (average variance extracted, AVE), and enhance the total variation of structural model (squared multiple correlation, $\mathrm{R}^{2}$ ). The process of construct validation was conducted as shown in Table 1. Construct validation is comprised of AVE, MSV, ASV, and discriminant validity. This step is a major part in the validation process which determines to what extent the measurement model is well-defined, reliable, and accurate. If fitness is conducted to test the fit model, the validation phase should be performed to approve the measurement model. During the evaluation process (fitness index and multidimensional procedure), this step can be known as exploratory modeling to determine the characteristics and behavior of the measurement model. Thus, validation step is suggested as an important phase in confirmatory model. If the validation test meets the requirements, then, all the measurement model that
Table 1. Reliability and construct validity

\begin{tabular}{lllll}
\hline & CR & AVE & MSV & ASV \\
\hline Population Growth & 0.905 & 0.826 & 0.701 & 0.461 \\
Government Support & 0.895 & 0.632 & 0.564 & 0.390 \\
Climate Changes & 0.870 & 0.773 & 0.564 & 0.236 \\
Public Attitude & 0.863 & 0.683 & 0.570 & 0.349 \\
Environment & 0.934 & 0.876 & 0.701 & 0.428 \\
Dengue Fever & 0.856 & 0.601 & 0.496 & 0.374 \\
\hline
\end{tabular}

undergoes CFA can be successfully measured for the estimation and hypothesis testing. Most of the research articles, review papers, commentary papers, and proceeding usually have investigated AVE for validation process. In fact, there are other validation approaches such as average shared variance (ASV) and maximum shared variance (MSV) that can be calculated manually. Fornell and Larcker (1981) reported that AVE should be higher than 0.50 or $50 \%$ for each exogenous constructs in measurement model (37). This scale seems to be essential to verify the strength of measurement model, in particular, $50 \%$ of the total variation in measurement model has been captured by measuring manifest variable to show the impact of this model. If the model captures a variation below $50 \%$, the model will be inadmissible for validation step.

Afterwards, MSV and ASV were calculated using a formula proposed by Fornell and Larcker (37). To give more information about calculation of MSV and ASV to the reviewer and readers of this study, government support construct was first outlined. For government support construct, this model consisted five correlations with respect to climate changes (0.75), public attitude (0.51), environment (0.58), population growth (0.63), and dengue fever (0.63). MSV formula showed the highest correlation which indicates the maximum total variation. In contrast with all these correlations, the correlation between government support and climate changes was higher than that of government support with public attitude, environment, population growth, and dengue fever ( 0.75 vs 0.51 vs 0.58 vs 0.63 vs 0.63 ). It means that the calculation for MSV is $0.751^{2}=0.564$ and is suggested valid when this value is lower than AVE as reported in Table 1. To calculate ASV, the formula $\left(0.75^{2}+0.51^{2}\right.$ $\left.+0.58^{2}+0.63^{2}+0.63^{2}\right) / 5=0.390$ was used, and it was repeated to calculate ASV for other constructs.

Analysis of the results of ASV and MSV shows that the measurement model is completely valid. The composite reliability (CR) highlighted in this model enable us to identify to what extent is the model reliable once performing CFA approach. Cronbach alpha has been usually used in empirical research to determine the reliability of the model (38). However, a study by Nunnally and Bernstein reported that Cronbach alpha is inappropriate to determine the reliability of the model 
in SEM application (39). This is because the traditional Cronbach alpha assume all eigenvalue of each items included in the model as 1 without considering the factor loadings provided by SEM.

Thus, CR has been proposed to determine factor loading and error variance solely in heterogeneous modeling $(38,39)$. In addition, measurement of factor loadings or outer loadings is appropriate to be emphasized since meet SEM assumptions in terms of efficiency and sufficiency estimator rather than Cronbach alpha. In this case, CR was reported as one of the reliability test for each measurement model. CR can also be well-known as Jöreskog's rhô that focuses on factor loadings and error variance. Discriminant validity was performed as shown in Table 2. Discriminant validity can be perceived at two angles in determining validity such as bivariate correlation and variation in measurement model. Bivariate correlation should be below $0.85(25,34,36)$ to consider the constructs involved in a research model are free from the detrimental effects of multicollinearity problem.

Moreover, the bold values in Table 2 show the square root of AVE and bivariate correlation. Every square root of AVE should be higher than all construct correlations whether in rows or columns provided. AVE with a higher scale that exceeds the scale of bivariate correlation shows that the variation in measurement model is absolutely high compared to the correlation of measurement model. Overall, it was found that the measurement model suggested in this study meet the total requirements in terms of fitness index, multidimensional procedure, factor loadings, reliability and validity test, and therefore, is suitable for the structural model.

\section{Structural Model}

Then, structural model was implemented based on the theoretical framework suggested. For this purpose, 9 research hypotheses were provided and tested using SEM and the CFA approach as aforementioned. After implementation of CFA approach, the structural model was conducted to test the hypotheses. At this stage, parameter estimation and hypothesis testing (probability value) were performed for each research hypothesis. Figure 2 shows the structural model and Table 3 shows the results of each hypotheses.

Table 2. Discriminant validity

\begin{tabular}{lllllcc} 
& Population Growth & Government Support & Climate Changes & Public Attitude & Environment & Dengue Fever \\
\hline Population Growth & 0.909 & 0.635 & 0.391 & 0.755 & 0.797 \\
Government Support & 0.635 & 0.795 & 0.751 & 0.506 & 0.577 \\
Climate Changes & 0.391 & 0.751 & 0.879 & 0.369 & 0.392 \\
Public Attitude & 0.755 & 0.506 & 0.369 & 0.826 & 0.675 \\
Environment & 0.797 & 0.577 & 0.392 & 0.675 & 0.917 \\
\hline Dengue Fever & 0.691 & 0.629 & 0.417 & 0.574 & 0.704 \\
\hline
\end{tabular}

Table 3. Hypothesis testing

\begin{tabular}{|c|c|c|c|}
\hline Research Hypothesis & Estimate & $P$ value & Significant $(\alpha=0.05)$ \\
\hline $\mathrm{H}_{1}$ : Government support has a significant impact on the environment & 0.039 & 0.579 & No \\
\hline $\mathrm{H}_{1}$ : Climate changes have a significant impact on the environment & 0.044 & 0.375 & No \\
\hline $\mathrm{H}_{1}$ : Public attitude has a significant impact on the environment & 0.196 & 0.005 & Yes \\
\hline $\mathrm{H}_{1}$ : Population growth has a significant impact on the environment & 0.736 & $* * *$ & Yes \\
\hline $\mathrm{H}_{1}$ : Government support has a significant impact on dengue fever & 0.305 & $* * *$ & Yes \\
\hline $\mathrm{H}_{1}$ : Public attitude has a significant impact on dengue fever & 0.116 & 0.045 & Yes \\
\hline $\mathrm{H}_{1}$ : Population growth has a significant impact on dengue fever & 0.091 & 0.285 & No \\
\hline $\mathrm{H}_{1}$ : Climate changes have a significant impact on dengue fever & -0.058 & 0.214 & No \\
\hline $\mathrm{H}_{1}$ : Environment has a significant impact on dengue fever & 0.280 & $* * *$ & Yes \\
\hline Exogenous Constructs & \multicolumn{3}{|c|}{ Standardized Total Effect on Dengue Fever } \\
\hline Government support & \multicolumn{3}{|l|}{0.371} \\
\hline Climate changes & \multicolumn{3}{|l|}{-0.590} \\
\hline Public attitude & \multicolumn{3}{|l|}{0.168} \\
\hline Population growth & \multicolumn{3}{|l|}{0.347} \\
\hline Environment & \multicolumn{3}{|l|}{0.360} \\
\hline Exogenous Constructs & \multicolumn{3}{|c|}{ Standardized Total Effect on Environment } \\
\hline Government support & \multicolumn{3}{|l|}{0.035} \\
\hline Climate changes & \multicolumn{3}{|l|}{0.045} \\
\hline Public attitude & \multicolumn{3}{|l|}{0.160} \\
\hline Population growth & \multicolumn{3}{|l|}{0.670} \\
\hline
\end{tabular}




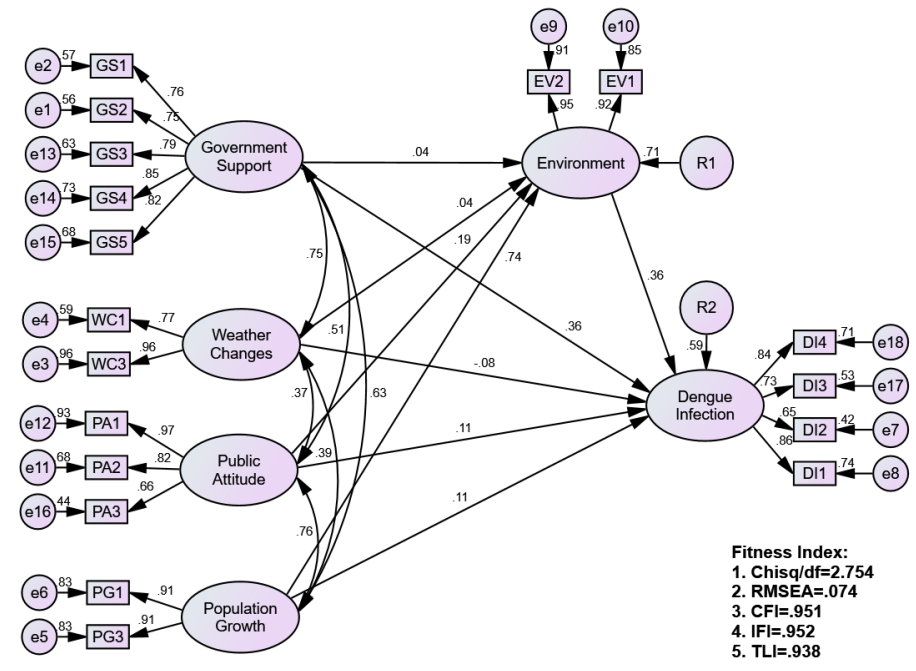

Figure 2. Structural model.

\section{Discussion}

Direct effect $(\rightarrow)$ can be known as the causal effect that is imposed by exogenous construct to endogenous construct. In this stage, four exogenous constructs including government support, climate changes, public attitude, and population growth were suggested to affect mediator construct (environment) and endogenous construct (dengue fever). The correlational path $(\leftrightarrow)$ is indicated as covariance path in unstandardized estimate to determine the covariance path for each exogenous construct. Nevertheless, the aim of this research was to test the research hypotheses mentioned previously. Figure 2 shows the structural model of dengue fever for obtaining parameter estimate and hypothesis testing (probability value). It was found that this study is adequate since the model achieved 0.590 or $59 \%$ of dengue infection, which is higher than half of the total variation. It means that $59 \%$ of the total variation of dengue fever came from these exogenous. Thus, $100 \%-59 \%=41 \%$ of the total variation came from other constructs that may have the potential to associate with dengue fever. In terms of environment as one of the mediator construct, SEM application reveals that $71.5 \%$ of the total variation came from four exogenous constructs as shown in Figure 2. Therefore, 28.5\% of the total variation may come from other constructs that can be related to the mediator construct.

Overall, three exogenous constructs including government support, public attitude, and environment have significant impacts on dengue fever. In other words, it was confirmed that these exogenous constructs have a positive impact on dengue fever, which is one of the main public health issues in Malaysia. In addition, two constructs, namely public attitude and population growth have a significant positive impact on the environment. According to this result, it is confirmed that public attitude and population growth should be emphasized since these constructs have a significant effect on dengue fever. In order to identify the most important construct affecting dengue fever and environment, standardized total effect was used as a tool in this study.

As shown in Table 3, government support is the most important construct that has a significant effect on dengue fever. However, the results of measurement of mediator construct show that population growth is the most important construct that has a high effect on the environment. The finding is based on the Likert scale, through which the attitude of respondent towards the issue presented was measured.

\section{Conclusion}

Using SEM itself, it was revealed that the results of this study on dengue fever that emanating from four exogenous and one mediator constructs are adequate to discuss on respondent perception of dengue fever in Malaysia as illustrated by $\mathrm{R}^{2}=0.59$ or $59 \%$. So, it is claimed that this research is absolutely adequate to measure the respondent perception of dengue fever. As shown in Table 3, the respondents confirm that public attitude and population growth factors have a causal effect on the environment. In reality, most of our citizens do not pay attention to the environment issues even our government promotes various campaigns so that we will undertake this responsibility as a good citizen. They are not aware of the environmental sustainability that should be maintained for the next generation. For instance, the amount of waste is increasing every year that is reaching almost 3 million tons per year.

In addition, the population growth was also addressed by respondent perception. They opined that population growth can influence the performance of the environment. As we can see today, the human capital that coming from Nepal, Myanmar, Bangladesh, Indonesia, and India are increasing every year to penetrate the labor market especially through physical infrastructure improvement. 
A high-skilled nation infrastructure is required in line with our goal to achieve a developed nation by 2020 as suggested by the fourth Prime Minister of Malaysia, Datuk Seri Mahathir Mohamad. Therefore, the growing population growth primarily would cause a wide range of side effects on our environment. This is because majority of foreign workers are usually ignoring the cleanliness, and subsequently, cause the local people getting mad and uncomfortable. Although population growth has a significant effect on environment but this factor has no effect on the occurrence of dengue fever. It means that the respondents confirmed that the environment can be affected by the population growth, but it cannot be a determinant of dengue fever.

A study by Hales et al showed that climate changes have a potential effect on the spread of dengue fever (40), which is inconsistent with the results of the present study, indicating climate changes have no significant effect on the environment and dengue fever. In fact, this infection is not a new phenomenon in Malaysia and it was reported for the first time in 1902. Thus, the situation in this country is not the same as other countries

It was also found that three exogenous constructs including public attitude, government support, and environment are associated with each other and have a significant impact on dengue fever in Malaysia. For instance, good public attitudes with government support would contribute to a high-performance environment to overcome the spreading of dengue fever. Therefore, these factors should be highlighted to solve this particular issue using a good strategy and planning. In order to restrict the spreading of dengue fever, the most important factors were government support (0.371), environment (0.360), population growth (0.347), public attitude (0.167), and climate changes $(-0.590)$, respectively. Therefore, government should take an affirmative action to tackle this particular issue. Besides raising awareness of people about dangerous dengue fever, they can provide better facilities to the patients. For this purpose, the government can provide an adequate number of beds, physicians, and space for the patient so that the medical treatment can be handled very well. Besides, clinics should be extended to the rural areas since these areas are significantly affected by dengue fever. In addition, the fogging program should not be supposedly active in the presence of dengue fever, instead, it can be practically implemented once every three months. This program would be definitely retarded the growth of Aedes, the yellow fever mosquito, especially in the stagnant areas.

In terms of environment factor, population growth is perceived as the most important factor which affects the environment. This factor has been discussed in recent decades since developing and less-developed countries have to face many challenges to compete with other countries, which is consistent with the results reported by Ehrlich and Holdren, indicating that population growth would have a negative effect on the environment (41). Some studies also showed that there is a positive relationship between population growth and the environment $(41,42)$, which is consistent with the results of this study.

However, future studies are suggested to replace insignificant factors with other factors such as hightech medicine that can be associated with dengue fever. Additionally, the potential of moderating effect or multigroup analysis can be applied using the same particular method, SEM. Using this technique, other moderator factor that may affect the relationship of exogenous constructs with dengue fever, can be identified. Moreover, the sampling should be extended to other areas so that the estimates obtained can be really representative to explain the whole perception of respondents towards dengue fever.

\section{Acknowledgements}

The authors would like to gratitude Prof. Zainudin Awang for his good supervision and brilliant ideas to support this study. And special thanks to all friends and colleagues especially from Universiti Sultan Zainal Abidin (UniSZA), Malaysia, who supported authors to complete this research.

\section{Ethical issues}

The authors hereby certify that all data collected during the research are as expressed in the manuscript, and this paper has not been published elsewhere.

\section{Competing interests}

The authors declare that they have no conflict of interests.

\section{Authors' contribution}

All authors contributed equally to this research. In particular, the first author focused on writing, data interpretation and analysis, and technical parts. The second author involved in conducting statistical analysis, data collection, and editing the final manuscript.

\section{References}

1. Saifuddin TM, Ismail AF, Haru NA. Late onset mania post dengue fever in an elderly patient: a case report. Malaysian Journal of Psychiatry 2018; 27(1): 37-40.

2. Heilman JM, De Wolff J, Beards GM, Basden BJ. Dengue fever: a Wikipedia clinical review. Open Med 2014; 8(4): e105-15.

3. Ismail Z. The dengue menace. [cited 2017 Feb 15] Available from: https://www.thestar.com.my/Lifestyle/ Health/2014/02/09/The-dengue-menace.

4. Wong LP, Alias H, Aghamohammadi N, Sam IC, AbuBakar S. Differences in perceived severity of Zika virus infection and dengue fever and its influence on mosquito control practices in Malaysia. J Community Health 2017; 42(5): 854-64. doi: 10.1007/s10900-017-0326-7.

5. Gubler DJ. Dengue and dengue hemorrhagic fever. Clin Microbiol Rev 1998; 11(3): 480-96. 
6. Focks DA, Daniels E, Haile DG, Keesling JE. A simulation model of the epidemiology of urban dengue fever: literature analysis, model development, preliminary validation, and samples of simulation results. Am J Trop Med Hyg 1995; 53(5): 489-506. doi: 10.4269/ajtmh.1995.53.489.

7. Iqbal N, Islam M. Machine learning for dengue outbreak prediction: an outlook. Int J Adv Res Comput Sci 2017; 8(1): 93-102. doi: 10.26483/ijarcs.v8i1.2859.

8. Kyle JL, Harris E. Global spread and persistence of dengue. Annu Rev Microbiol 2008; 62: 71-92. doi: 10.1146/annurev. micro.62.081307.163005.

9. Parks WJ, Lloyd LS, Nathan MB, Hosein E, Odugleh A, Clark GG, et al. International experiences in social mobilization and communication for dengue prevention and control. Dengue Bull 2004; 28: 1-7.

10. Hossain MI, Wagatsuma Y, Chowdhury MA, Ahmed TU, Uddin MA, Sohel SN, et al. Analysis of some sociodemographic factors related to DF/DHF Outbreak in Dhaka city. Dengue Bull 2000; 24: 34-41.

11. Patz JA, Martens WJ, Focks DA, Jetten TH. Dengue fever epidemic potential as projected by general circulation models of global climate change. Environ Health Perspect 1998; 106(3): 147-53. doi: 10.1289/ehp.98106147.

12. Gubler DJ, Meltzer M. Impact of dengue/dengue hemorrhagic fever on the developing world. Adv Virus Res 1999; 53: 35-70. doi: 10.1016/s0065-3527(08)60342-5.

13. Feng Z, Velasco-Hernández JX. Competitive exclusion in a vector-host model for the dengue fever. J Math Biol 1997; 35(5): 523-44. doi: 10.1007/s002850050064.

14. Monath TP. Dengue: the risk to developed and developing countries. Proc Natl Acad Sci U S A 1994; 91(7): 2395-400. doi: 10.1073/pnas.91.7.2395.

15. Zanotto PM, Gould EA, Gao GF, Harvey PH, Holmes EC. Population dynamics of flaviviruses revealed by molecular phylogenies. Proc Natl Acad Sci U S A 1996; 93(2): 548-53. doi: 10.1073/pnas.93.2.548.

16. Hopp MJ, Foley JA. Global-scale relationships between climate and the dengue fever vector, Aedes aegypti. Climatic Change 2001;48(2):441-63. doi: 10.1023/A:1010717502442.

17. Nakhapakorn K, Tripathi NK. An information value based analysis of physical and climatic factors affecting dengue fever and dengue haemorrhagic fever incidence. Int $\mathrm{J}$ Health Geogr 2005; 4: 13. doi: 10.1186/1476-072x-4-13.

18. Derouich M, Boutayeb A, Twizell EH. A model of dengue fever. Biomed Eng Online 2003; 2: 4. doi: 10.1186/1475925x-2-4.

19. Thammapalo S, Chongsuvivatwong V, Geater A, Dueravee M. Environmental factors and incidence of dengue fever and dengue haemorrhagic fever in an urban area, Southern Thailand. Epidemiol Infect 2008; 136(1): 135-43. doi: $10.1017 / \mathrm{s} 0950268807008126$.

20. Hair JF, Black WC, Babin BJ, Anderson RE. Multivariate Data Analysis: A Global Perspective. New Jersey: Pearson Prentice Hall; 2010. p. 661-99.

21. Afthanorhan A, Foziah H, Rusli R, Khalid S. The effect of service quality on customer satisfaction in three campuses of UniSZA. International Journal of Innovation, Creativity and Change 2019; 7(10): 42-56.

22. Aziz MI, Adnan AA, Afthanorhan A, Foziah H, Ishak SI, Rashid N. The influence of employer value proposition in talent demand towards talent shortage in the Malaysian
Islamic banking institutions: a SEM approach. Manag Sci Lett 2019; 9(6): 843-50. doi: 10.5267/j.msl.2019.3.004.

23. Mohamad M, Afthanorhan A, Awang Z, Mohammad M. Comparison between CB-SEM and PLS-SEM: testing and confirming the Maqasid Syariah quality of life measurement model. J Soc Sci Res 2019; 5(3): 608-14. doi: 10.32861/ jssr.53.608.614.

24. Dalila D, Latif H, Jaafar N, Aziz I, Afthanorhan A. The mediating effect of personal values on the relationships between attitudes, subjective norms, perceived behavioral control and intention to use. Manag Sci Lett 2020; 10(1): 153-62. doi: 10.5267/j.msl.2019.8.007.

25. Asnawi AA, Awang Z, Afthanorhan A, Mohamad M, Karim F. The influence of hospital image and service quality on patients' satisfaction and loyalty. Manag Sci Lett 2019; 9(6): 911-20. doi: 10.5267/j.msl.2019.2.011.

26. Afthanorhan A, Awang Z, Fazella S. Perception of tourism impact and support tourism development in Terengganu, Malaysia. Soc Sci 2017; 6(3): 106. doi: 10.3390/ socsci6030106.

27. Afthanorhan A, Awang Z, Salleh F, Ghazali P, Rashid $\mathrm{N}$. The effect of product quality, medical price and staff skills on patient loyalty via cultural impact in medical tourism. Manag Sci Lett 2018; 8(12): 1421-4. doi: 10.5267/j. msl.2018.10.004.

28. Mohamad M, Ali AM, Ghani NI, Abdullah AR, Mokhlis S. Positioning Malaysia as a tourist destination based on destination loyalty. Asian Soc Sci 2012; 9(1): 286-92. doi: 10.5539/ass.v9n1p286.

29. Aimran AN, Ahmad S, Afthanorhan A, Awang Z. The development of comparative bias index. AIP Conf Proc 2017; 1870(1): 060008. doi: 10.1063/1.4995935.

30. Aimran AN, Ahmad S, Afthanorhan A, Awang Z. The assessment of the performance of covariance-based structural equation modeling and partial least square path modeling. AIP Conf Proc 2017; 1842(1): 030001. doi: $10.1063 / 1.4982839$.

31. Fabrigar LR, Wegener DT, MacCallum RC, Strahan EJ. Evaluating the use of exploratory factor analysis in psychological research. Psychol Methods 1999; 4(3): 27299. doi: 10.1037/1082-989X.4.3.272.

32. Ford JK, MacCallum RC, Tait M. The application of exploratory factor analysis in applied psychology: a critical review and analysis. Pers Psychol 1986; 39(2): 291-314. doi: 10.1111/j.1744-6570.1986.tb00583.x.

33. Gorsuch RL. Exploratory factor analysis: its role in item analysis. J Pers Assess 1997; 68(3): 532-60. doi: 10.1207/ s15327752jpa6803_5.

34. Abd Majid N, Zainol FA, Daud WN, Afthanorhan A. Cooperative entrepreneurship in malaysian secondary schools: a review of current practices. The Journal of Social Sciences Research 2019; 5(3): 812-8.

35. Holmes-Smith P, Coote L, Cunningham E. Structural Equation Modeling: From the Fundamentals to Advanced Topics. Melbourne: Streams Statsline; 2006.

36. Nasir M, Mohamad M, Ghani N, Afthanorhan A. Testing mediation roles of place attachment and tourist satisfaction on destination attractiveness and destination loyalty relationship using phantom approach. Manag Sci Lett 2020; 10(2): 443-54. doi: 10.5267/j.msl.2019.8.026.

37. Fornell C, Larcker DF. Evaluating structural equation models 
with unobservable variables and measurement error. J Mark Res 1981; 18(1):39-50. doi: 10.1177/002224378101800104.

38. Nunnally JC, Bernstein IH. Psychometric Theory. New York: McGraw-Hill; 1994.

39. Nunnally JC, Bernstein IH, Berge JMT. Psychometric Theory. New York: McGraw-Hill; 1967.

40. Hales S, de Wet N, Maindonald J, Woodward A. Potential effect of population and climate changes on global distribution of dengue fever: an empirical model. Lancet 2002; 360(9336): 830-4. doi: 10.1016/s01406736(02)09964-6.

41. Ehrlich PR, Holdren JP. Impact of population growth. Science 1971; 171(3977): 1212-7. doi: 10.1126/ science.171.3977.1212.

42. Sherbinin AD, Carr D, Cassels S, Jiang L. Population and environment. Annu Rev Environ Resour 2007; 32:345-73. 